\title{
Culture and Egocentric Perceptions of Fairness in Conflict and Negotiation
}

\author{
Michele J. Gelfand, Marianne Higgins, \\ Lisa H. Nishii, Jana L. Raver, and \\ Alexandria Dominguez \\ University of Maryland
}

Fumio Murakami and Susumu Yamaguchi

University of Tokyo

\author{
Midori Toyama \\ Osaka University
}




\begin{abstract}
In this article, the authors advanced a cultural view of judgment biases in conflict and negotiation. The authors predicted that disputants' self-serving biases of fairness would be more prevalent in individualistic cultures, such as the United States, in which the self is served by focusing on one's positive attributes to "stand out" and be better than others, yet would be attenuated in collectivistic cultures, such as Japan, where the self is served by focusing on one's negative characteristics to "blend in" (S. J. Heine, D. R. Lehman, H. R. Markus, \& S. Kitayama, 1999). Four studies that used different methodologies (free recall, scenarios, and a laboratory experiment) supported this notion. Implications for the science and practice of negotiation are discussed.
\end{abstract}


One of the most important advances in conflict and negotiation research in the past 2 decades has been the identification of judgment biases that can ultimately inhibit negotiation agreements (Bazerman \& Carroll, 1987; Thompson, 1990). Much research, for example, has illustrated that negotiators tend to have fixed-pie perceptions of negotiations (Thompson \& Hastie, 1990), fail to recognize compatible interests (Thompson \& Hrebec, 1996), devalue concessions made by their counterparts (Stillenger, Epelbaum, Keltner, \& Ross, 1991), experience less satisfaction when their counterparts are happy than when disappointed (Thompson, Valley, \& Kramer, 1995), and become stuck in impasse because of self-serving biases and overconfidence (Babcock \& Loewenstein, 1997; Thompson \& Loewenstein, 1992). Many of these competitive biases are pervasive, and thus their identification has not only theoretical importance for understanding the psychology of negotiation but also practical importance for training negotiators to be more effective.

Nevertheless, to date, virtually all of the theories and research on judgment biases in negotiation have been derived from Western contexts. As such, the question of whether such biases generalize to other cultures remains largely unanswered. One view of judgment biases-a view which is often espoused in the literature-is that they are reflective of cognitive shortcuts that all humans use to manage information-processing demands to cope with their overtaxed cognitive systems. Viewed within this perspective, judgment biases should be universal. In this article, we present an alternative view, namely that judgment biases in negotiation may be reflections of different cultural imperatives that negotiators have internalized as part of their self systems. We argue that rather than being due to universal "shortcuts," biases in negotiation may be culturally constructed and perpetuated.

More specifically, we focus on the universality of one judgment bias in negotiation-self-serving biases of fairness - which have been found to be pervasive in Western contexts. As reviewed below, 
negotiators in the United States consistently view their own behaviors as more fair than those of their counterparts, and such biases seriously impede the resolution of disputes. We question the universality of this judgment bias and argue instead that when studying self-serving biases in negotiation, we must consider the nature of the self being served in a particular cultural context. We argue that self-serving biases in negotiation are consistent with cultural ideals within individualistic cultures, in which the self is served by enhancing one's positive attributes to "stand out" and be better than others (Heine \& Lehman, 1995; Heine, Lehman, Markus, \& Kitayama, 1999). However, we expected that self-serving biases in negotiation would be attenuated in collectivistic cultures, in which the self is served by focusing on one's negative characteristics to "blend in" and maintain interdependence with others. Thus, we posited that self-serving biases in negotiation are not universal but rather are dependent on views of the self that are cultivated within individualistic contexts. Below, we provide an overview of research on self-serving biases, describe the literature on culture and the self, and then describe four studies that examined the universality of self-serving biases in conflict and negotiation.

\section{Self-Serving Biases in Perception}

Dating back to Miller and Ross's (1975) discussion of self-serving biases in the attribution of causality, researchers have found that people have a pervasive tendency to see themselves as better than others. This bias has been found across numerous domains; research has illustrated that people perceive themselves as more fair (Messick, Bloom, Boldizar, \& Samuelson, 1985), more competent (Yan \& Gaier, 1994), more successful (Urban \& Witt, 1990), more socially responsible (White \& Plous, 1995), and more responsible for success and less responsible for failure than others (Mark, Mutrie, Brooks, \& Harris, 1985). In fact, even after people are trained to understand the existence of self-serving biases, they still report being less likely to engage in the self-serving bias than others (Friedrich, 1996)! These 
judgments are not only probabilistically impossible (i.e., it is impossible for most people to be better than others) but are also much inflated as compared with neutral raters' observations (Lewinsohn, Mischel, Chaplin, \& Barton, 1980).

In recent years, negotiation scholars have expanded on this literature by documenting the pervasiveness of self-serving biases in the context of dynamic interactions. For example, Kramer, Newton, and Pommerenke (1993) found that negotiators in the United States had overly positive evaluations of themselves as compared with their counterparts (e.g., they believed they were more fair, trustworthy, and cooperative) and that the magnitude of such biases was related to the strength of the conflict. Similarly, Thompson and Loewenstein (1992) found that negotiators had self-serving conceptions of fairness and that such biases were related to the length of strikes during simulated negotiations. Indeed, studies have demonstrated that self-serving biases are evident among professional negotiators and that such biases are related to impasses (Loewenstein, Issacharoff, Camerer, \& Babcock, 1993), length of strikes (Babcock, Wang, \& Loewenstein, 1996), and reduced problem-solving and feelings of frustration (de Dreu, Nauta, \& Van de Vliert, 1995). In summarizing this literature, Babcock and Loewenstein (1997) concluded that negotiators' tendencies to equate what is fair with what benefits themselves impedes negotiations by reducing the potential zone of agreement, by creating cynical perceptions of the other party, and by inflating perceptions of the minimum settlement point that is seen as fair.

In sum, there is substantial evidence that people in general, and negotiators in particular, have overly inflated views of themselves, and such biases have deleterious consequences on the settlement of disputes. Within the cognitive tradition in negotiation, such pervasive tendencies are generally assumed to be manifestations of cognitive shortcuts that negotiators use because of their limited information processing capabilities. Although not disputing the value of this approach, below we 
introduce an alternative perspective- a cultural perspective-on self-serving biases in negotiation. We argue below that although often presumed to be a universal phenomenon, the robustness of selfserving biases in negotiation is reflective of a view of the self that is dominant within individualistic cultures.

\section{Culture, Self, and Negotiation}

One fundamental issue that societies must confront is the nature of the relationship between the individual and the group, which has been referred to as individualism- collectivism (Hofstede, 1980; Triandis, 1995). In recent years, much research has illustrated that the nature of the self varies across individualistic and collectivistic cultures, which is most relevant to our theory on culture and self-serving biases in negotiation. In individualistic cultures, such as that of the United States, the self is generally construed as separate, detached, and independent from the social context, and individuals focus on their own internal attributes - their preferences, abilities, and traits-as key aspects of the self (Markus \& Kitayama, 1991). The cultural ideal is to be separate from others, to develop and affirm one's attributes, and most important, to feel positive about oneself (Markus, Kitayama, \& Heiman, 1996). These cultural ideals of uniqueness and self-enhancement are instilled in children from as early as 4 years of age (Harter, 1990; Kitayama, Markus, Matsumoto, \& Norasakkunkit, 1997; Snow, 1996) and are reinforced in American schools, where children are taught to identify their positive attributes, to feel special, and to think of themselves as "stars" (Markus, Mullally, \& Kitayama, 1997). In the larger cultural context, popular proverbs (e.g., "Winning isn't everything-it's the only thing"), advertisements (e.g., "Be all you can be"), and heroes (e.g., Michael Jordan) all reinforce that it is important to be different from, and better than, others. Not surprisingly, individuals socialized in such cultural systems are motivated to focus on their positive attributes in ways that make them stand out. Indeed, as reviewed 
above, research has consistently found that Americans view themselves as better than others (see Heine, et al., 1999, for a review).

Although such tendencies are natural in cultural systems in which the self is construed as independent, they are antithetical to cultural systems that cultivate and sustain views of the self as interdependent. In collectivistic cultures such as that of Japan, the self is generally construed as fundamentally connected to others, and one is largely defined in terms of one's roles, statuses, and obligations (Markus \& Kitayama, 1991). The cultural ideal is to maintain relatedness and to adjust one's behavior to better fit in and be accepted by others (Markus \& Kitayama, 1991). As noted by Markus et al. (1996), in such cultural systems, the validation of positive attributes that are distinct from and better than others is seen as disruptive to cultural ideals of harmony and relatedness. Indeed, in contrast to the emphasis on self-enhancement among American parents, Japanese parents teach their children that focusing on their uniqueness and positive attributes will weaken the solidarity of the group and will lead to alienation from others (Markus et al., 1996). Rather than helping children to identify their positive characteristics through praise and compliments, Japanese teachers encourage students to focus on their shortcomings and weaknesses through hansei, or critical self-reflection, to adapt and fit in with others (Heine et al., 1999). This continuous process of being self-critical and improving oneself serves as an affirmation of one's interdependence with others and of being a "good" cultural self (Heine et al., 1999; Markus et al., 1996). These practices continue in organizations, where the achievement of wa (i.e., harmony) and being integrated into workgroups is emphasized over being distinctive and standing out (Kashima \& Callan, 1994).

In sum, the nature of the self, and thus the ways in which the self is served, varies in individualistic and collectivistic cultures (Heine et al., 1999; Markus \& Kityama, 1991). The self is served in individualistic cultures by being distinct from and better than others, in order to accomplish the 
culturally mandated task of being independent and standing out. By contrast, the self is served in collectivistic cultures by being accepted by others and by focusing on negative characteristics, in order to accomplish the culturally mandated task of being interdependent and blending in.1 Most pertinent to this research, this analysis suggests that self-serving biases within negotiation are not necessarily universal, but rather may be more prevalent in particular sociocultural contexts. We expected that the tendency to view one's behavior as superior to that of other negotiators would be more prevalent in individualistic cultures (e.g., the United States), which emphasize the importance of uniqueness and being better than others, as compared with collectivistic cultures (e.g., Japan), which emphasize selfcriticism and maintaining relatedness with others. Four studies investigated this proposition.2

\section{Study 1}

In Study 1 we examined the degree to which individuals in the United States and Japan engaged in self-serving biases with regard to fairness. On the basis of the theory and research detailed above, we expected that individuals in the United States, who are socialized to maintain a positive view of the self that is distinct from and better than others, would perceive themselves as engaging in more fair behaviors and others as engaging in more unfair behaviors, as compared with Japanese (Hypothesis 1). To test this hypothesis, we used Messick et al.'s (1985) free-recall methodology. Specifically, students were asked to generate both fair and unfair behaviors and to indicate whether they engaged in such behaviors more than others ("I-fair" and "I-unfair") or whether others engaged in such behaviors more than them ("they-fair" and "they-unfair"). Because perceptions that the self is superior to others are important for individuals to feel good about themselves within individualistic cultures, we expected that Americans would have many more examples readily accessible in memory of themselves being fair ("Ifair") and others being unfair ("they-unfair"), as compared with Japanese. 


\section{Method}

Participants. A total of 159 upper-level undergraduate students from the United States $(\mathrm{N}=69)$ and Japan $(\mathrm{N}=90)$ participated in this study. The samples were highly similar with respect to most demographics. The mean age in both samples was 21 , and both samples included participants who were mainly of middle-class social status ( $87 \%$ in the United States and $90 \%$ in Japan). The Japanese sample was $30 \%$ men and $70 \%$ women, and the U.S. sample was $47 \%$ men and $53 \%$ women. Analyses with gender as a covariate did not change the results described below.

Procedure. Participants in the United States and Japan were asked to engage in a study investigating perceptions of social behavior. Following Messick et al. (1985), participants were given 5 min to write a list of as many fair behaviors as they could think of, and they were given 5 min to write a list of as many unfair behaviors as they could think of as well. For each list, they were told to start statements with the word I if the behavior was something they did more than other people and to start the sentence with They if it was something other people did more often than themselves. To control for order effects, half of the participants listed "fair" behaviors first, whereas the other half listed "unfair" behaviors first. There were no order effects for version. Pilot tests of this method revealed no problems in the understanding of the task or the instructions in either the United States or Japan. All materials were translated into Japanese and were back translated to check for equivalence of meaning.

Results

As per Messick et al. (1985), the dependent variables in this study included four scores: number of I-fair items, number of I-unfair items, number of they-fair items, and number of they-unfair items. A multivariate analysis of variance (MANOVA) revealed a significant effect for culture, $F(4,154)=21.95, p$ 
$>$.01. As seen in Figure 1, U.S. participants wrote significantly more I-fair items, $t(157)<8.9, p<.01$, and they-unfair items, $\mathrm{t}(157)$ 5.0, p .001, than did Japanese participants. Thus, U.S. participants showed a pronounced tendency to start unfair behaviors with They and fair behaviors with I, which is indicative of a self-serving bias. Consistent with Hypothesis 1, this tendency was greatly attenuated in Japan. In addition, following Messick et al. (1985), we created a self-serving bias score by subtracting the nonegocentric items (I-unfair + they-fair) from the egocentric items (I-fair + they-unfair). For this measure, the greater the positive difference between these scores, the more participants had egocentric perceptions of fairness. As expected, this score was much higher among Americans than Japanese, $t(157)=6.6, p<.001$ (U.S. $M=6.40, S E=0.63 ;$ Japanese $M=1.60, S E=0.40)$.

In sum, Study 1 illustrated that U.S. participants had greater self-serving perceptions of fairness as compared with Japanese participants. This method is useful in that it involved free recall and was relatively nonobtrusive. Nevertheless, because there are rival hypotheses in cross-cultural research, it is important to use multiple methodologies to seek convergence. As such, the next three studies examined culture and self-serving biases in additional contexts and with additional samples.

Study 2

In Study 2 we extended the investigation of culture and self-serving perceptions of fairness to naturally occurring conflicts in the United States and Japan. In this study, participants were asked to describe a conflict in which they had recently been involved and to evaluate it from the perspective of a third party. Because standing out and being better than others is important in individualistic cultures, 
we expected that as compared with Japanese disputants, U.S. disputants would be less likely to evaluate the conflict objectively and critically (because of a lack of hansei, or critical self-reflection) and would therefore report that another party would view their own behavior as much more fair than the other disputants' behavior (Hypothesis 2). In this respect, we expected that U.S. disputants would project their self-serving biases to that of an objective third party.

Methods

Participants. A total of 349 undergraduate students from the United States ( $N=144)$ and Japan $(\mathrm{N}=205)$ participated in this study. The sample was highly similar with regard to demographics such as age $(M=20.0$ in the United States; $M=19.8$ in Japan) and gender (45\% men, 54\% women, $1 \%$ unknown in the United States; $54 \%$ men, $46 \%$ women in Japan).

Procedure. All participants were asked to fill out a confidential questionnaire regarding the nature of a conflict situation in which they had recently been engaged. After describing the conflict, participants were asked, “From an objective third party's view, how do you think your behavior during the conflict would be perceived?" with four semantic differential items following this question: not at all fair versus very fair; not at all reasonable versus very reasonable; not at all moral versus very moral; and not at all proper versus very proper. All of these items were assessed on scales from 1 to 7 . Responses were highly interrelated $(\sigma=.85)$ and were averaged. They were also asked the following question regarding their counterpart's behavior: “From an objective third party's view, how do you think the other party's behavior during the conflict would be perceived?" with the same four items listed above ( $\sigma$ $=.89)$, which were averaged. All materials were translated into Japanese and were back-translated to check for equivalence of meaning. 
Results

Conceptually similar to Messick et al.'s (1985) measure from Study 1, our assessment of egocentric perceptions included measurements of the extent to which disputants believed that an objective third party would view their own behavior to be more fair, reasonable, moral, and proper as compared with their counterparts. Accordingly, egocentric biases were computed by subtracting averaged scores on perceptions of one's counterpart's behavior from perceptions of one's own behavior. In support of Hypothesis 2, an analysis of variance revealed a significant effect, $F(1,337)=$ 32.0, $p<.01$ (U.S. $M=2.18, S E=0.17$; Japan $M=0.96, S E=0.13$ ). As expected, U.S. participants were more likely to believe that an objective third party would perceive their behavior as more fair than the behavior of their counterparts', whereas this was reduced in Japan.

Study 2 demonstrated that self-serving biases were attenuated in Japan, illustrating that cultural differences in self-serving biases extend into the domain of conflict. Although this study provides additional evidence of our main proposition, the possibility remains that the conflicts that were recalled varied in the United States and Japan, thereby affecting the results. An even stronger test of the culture and self-serving bias hypothesis, therefore, would entail examining biases in the United States and Japan when participants are faced with an identical situation, which was the focus of the next study.

Study 3

Using a scenario methodology, in Study 3 we examined U.S. and Japanese participants' perceived fairness of an offer that was given by another negotiator. Previous research has shown that 
negotiators in the United States are reluctant to agree to what they perceive as inequitable settlements and that they inflate perceptions of the minimum settlement point that is seen as fair (Babcock \& Loewenstein, 1997; Thompson \& Loewenstein, 1992). In other words, negotiators tend to equate what is fair with what benefits themselves when evaluating offers from other negotiators. In the current study, the offer from the other negotiator was objectively attractive in that it enabled negotiators to earn most of what they desired on their most important issue while allowing them to obtain some value on their least important issue. However, given that negotiators in individualistic cultures are focused on enhancing the self, we expected that U.S. negotiators would demand an agreement that was even more favorable to the self (in terms of points achieved) in order for it to be considered fair, as compared with the Japanese. Therefore, we expected that U.S. negotiators would perceive the offer as less fair and would be more likely to reject the offer, as compared with Japanese negotiators (Hypothesis 3 ).

\section{Methods}

Participants. Fifty-six students participated in this study $(N=36$ in the United States; $N=23$ in Japan). The average age was 19.8 in Japan and 18.5 in the United States. The U.S. sample was $60 \%$ women and $40 \%$ men, and the Japanese sample was $86 \%$ women and $13 \%$ men. Gender was not correlated with any of the variables below. Experimental design and procedure. All participants were asked to read a negotiation scenario that was based on real-life situations. They were asked to take their role seriously and to respond how they would really behave if faced with a similar situation. The scenario was modeled after other integrative negotiation tasks (Gelfand \& Realo, 1999; Pruitt, 1981; Thompson \& Hastie, 1990). Specifically, all participants were given the role of a representative of a company that sells paintings ("The Gallery"). They were told that The Gallery might hire another 
company ("NDC Printing") to place an advertisement for a final sale. Participants were then given an issue chart for The Gallery with the point values and levels for each issue.

As can be seen in the Appendix, the four issues included (a) amount of discount off of the price for the ad; (b) number of colors to be printed in the ad; (c) amount of time until the bill for the ad must be paid; and (d) how many people would receive the ad. For each of these issues, there were five alternatives, or proposals, on which the negotiators could settle. Furthermore, each proposal had a certain number of points that represented the profit of the proposal to the negotiator. The issue chart was constructed such that one issue, circulation, was the most important issue to the participants. By contrast, the billing issue was least important to the participants. These two issues were integrative in structure such that by trading off value on one's most and least important issues, one could attain much more profit for oneself. From the perspective of effective bargaining, an attractive integrative solution in this situation would be to obtain a large percentage of profit on one's most important issue (e.g., 400,000 for circulation) by accepting less value on one's least important issue (e.g., 2 or 3 weeks for billing; Pruitt, 1981).

Measures. The dependent variable was participants' judgments of fairness of an offer from the other negotiator from NDC Printing. Specifically, we asked participants: "Suppose the NDC Printing representative offers you: $10 \%$ off for discount, 1 color, 3 weeks, and 400,000 circulation?" They were then asked: "How fair would you think this offer is?" ( 1 = very unfair to 7 = very fair) and "How likely is it that you would accept this offer?" ( 1 = very unlikely to 7 = very likely). Materials were translated into Japanese and were back-translated to check for discrepancies. 
Results

In support of Hypothesis 3, there was a main effect for culture on participants' perceptions of the fairness of the other negotiators' offer, $F(1,54)=6.66, p<.01$. U.S. participants believed that the offer was much less fair $(M=3.36)$ as compared with Japanese participants $(M=4.52)$. U.S. participants also indicated they would be less likely to accept the offer than Japanese participants, $F(1,54)=7.77, p<$ .01 (U.S. $M=2.73$; Japan $M=3.91$ ). There was also a high correlation between perceptions of fairness of the offer and the likelihood that the offer would be accepted $(r=.625, p<.01)$, illustrating the deleterious effects of self-serving biases on negotiation settlements.

Study 3 replicated our previous results by demonstrating that self-serving biases are attenuated in Japan and illustrated the effect when individuals were evaluating an identical negotiation situation. This study extended our previous findings into the domain of negotiation, providing a conceptual replication for Studies 1 and 2. Because this study provides only a static picture of negotiation, however, we next examined cultural influences on self-serving biases in a more dynamic laboratory study and examined their consequences for negotiation outcomes.

\section{Study 4}

In Study 4, individuals in the United States and Japan engaged in a negotiation simulation that was modeled after the task in Study 3. Consistent with our theory of the importance of standing out in cultures that emphasize the independent self, we examined the hypothesis that prior to negotiating, U.S. negotiators would report that they expected to be more fair than their counterparts during the negotiation (i.e., have more self-serving biases of fairness), as compared with Japanese negotiators (Hypothesis 4), and that as a result, U.S. negotiators would achieve lower profits, as compared with 
Japanese negotiators (Hypothesis 5). In this study, we also assessed negotiators' self-construals to provide more direct evidence of the link between culture and self-construals. In other words, rather than using country as a surrogate for culture, the theoretical notions presented earlier suggest that independent self-construals should be higher in the United States, that independent self-construals should be positively related to self-serving biases, and that self-serving biases should be negatively related to negotiation outcomes.

Last, we expected self-serving biases to be related to negotiators' sensemaking of performance after negotiations. We posited that U.S. negotiators would be more accepting of feedback stating that they were above average performers as compared with average and below average because positive feedback enables them to affirm their positive qualities and to stand out-a cultural imperative in the United States. By contrast, we expected that Japanese negotiators would be more accepting of negative feedback because it enables them to identify their weaknesses in order to improve and blend in-a cultural imperative in Japan (Hypothesis 6; see also Heine et al., 2000, 2001).

\section{Method}

Participants. One hundred eighty upper level undergraduate students participated in this study ( $N=94$ from the U.S.; $N=86$ from Japan). The samples were highly similar with respect to demographics such as age ( $M=20.0$ in the U.S.; 19.4 in Japan), marital status ( $99 \%$ single in both countries), and social economic class (approximately $9 \%$ upper class, $87 \%$ middle class, and 3\% lower class in both countries). With respect to gender, the U.S. sample was $55 \%$ men and $45 \%$ women, and the Japanese sample was $74 \%$ men and $26 \%$ women. Results controlling for gender were highly similar. 
Design and procedure. The design was a 2 (culture: United States or Japan) X 3 (negotiation performance feedback: positive, neutral, or negative) factorial design. Participants were randomly assigned to either a buyer (The Gallery) or seller (NDC Printing) role and were also randomly assigned to a feedback condition. All negotiation dyads were of the same gender and feedback condition.

The negotiation task required individuals to take on either the role of a buyer (The Gallery) or seller (NDC Printing) and negotiate over four issues (see the Appendix). Both the discount and the color issues were distributive in nature, in that the issues had the same priority for the negotiators and the point values for these issues were reversed. In this respect, one negotiator's loss on each of these issues was the other negotiator's gain. By contrast, the billing issue and the circulation issue were integrative in nature, in that the point values were reversed for each negotiator yet the issues did not have the same priority for each negotiator. Participants were told that an agreement would be reached only when they agreed to the same levels on all four issues. Pilot testing found that the instructions were clear and the task was engaging in both cultural contexts.

Each participant reviewed the materials separately and was given a negotiation quiz (to ensure understanding of the task) and a pre-negotiation questionnaire. One negotiator was then escorted to join the other in the negotiation room. This room included a tape recorder and an intercom box. These items were present to create the illusion that their negotiation was being listened to and recorded, which was done to make the feedback more believable (described below). Participants were given 15 min to negotiate. Thereafter, the experimenter recorded their final agreement, took the tape from the recorder, and escorted the participants back to their original rooms, where they were given a brief questionnaire about their agreement and perceptions of themselves and their counterparts (see the Measures section below). Participants were then told that they were at the last stage of the experiment and that they would be given written feedback on their performance for learning purposes. The 
experimenter then briefly left the room to presumably check on the feedback and then returned to tell the participant that the expert judging their performance needed more time to complete the evaluation. After participants were kept waiting for 5 more min, they were then told, "Thank you for waiting. Your feedback is ready now. A PhD student has rated your performance. His ratings are described in detail in this envelope." Participants were given the envelope and were left alone to review the feedback and to answer one final questionnaire.

Feedback conditions. Participants were randomly assigned to one of three feedback conditions: positive, equal, or negative. Their performance was allegedly rated on the "Negotiation Effectiveness Index" (N.E.I.), which had presumably been validated in a number of studies as an excellent measure of negotiation performance (citations of bogus studies were also listed). This index was described as assessing negotiator effectiveness according to negotiation processes and outcomes, negotiator communication and tactics, and the final agreement of the negotiation. They were told that their performance was being compared with all of the other participants who had engaged in this study (approximately 200 individuals). There were also spaces on this form for the average N.E.I. score (as a baseline) and the participant's N.E.I. score, which ranged from 1 (low negotiator effectiveness) to 9 (high negotiator effectiveness). The average score was always listed as 5.5, and the participant's score was listed as either 7.9, 5.6, or 3.1, depending on feedback condition.3

Measures. All participants were given a pre-negotiation questionnaire that assessed their perceptions of the expected fairness of themselves and their counterparts. Self-serving perceptions of fairness were assessed by asking participants to rate how fair, trustworthy, and honest they expected themselves to be in the negotiation ( $\alpha=.63$ ) and how fair, trustworthy, and honest they expected the other person to be in the negotiation $(\alpha=.72)$, each on 7-point scales. Negotiation outcomes were measured through the total number of points earned in the negotiation across the four issues. We also 
included Singelis's (1994) self-construal scale at the end of the negotiation (and before the feedback) to examine whether the U.S. sample was in fact more individualistic than the Japanese sample. As expected, participants in the United States scored significantly higher on independence than did participants in Japan (U.S. $M=70.71 ;$ Japan $M=63.93$ ), $F(1,178)=23.10, p<.01 .{ }^{4}$ Last, reactions to feedback were assessed through several questions including: perceptions of the N.E.I. ("To what extent do you think the N.E.I. captures you as a negotiator?"), the confidence they placed in the feedback ("How confident are you that this feedback accurately reflects your abilities?"), and their acceptance of the feedback ("To what extent do you take personal responsibility for this feedback?"), all of which were on 7-point scales (from $1=$ not at all to $7=$ very much).

Results

Consistent with Messick et al. (1985), to derive an overall measure of self-serving bias, we subtracted participants' estimations of their own expected fairness before the negotiation from their estimations of the other person's expected fairness. Positive scores on this index indicate the degree to which participants had egocentric perceptions. In support of Hypothesis 4, prior to the negotiation, U.S. negotiators expected that they would be more fair than their counterparts as compared with Japanese negotiators, $F(1,86)=10.72, p<.01$ (U.S. $M=2.43, S E=0.39$; Japan $M=0.80, S E=0.30)$. In addition, consistent with the theory presented, we also found that independent self-construals were significantly related to egocentric perceptions of fairness: Dyads with more independent self-construals had greater egocentric biases, $F(1,86)=4.03, \beta=.21, p<.05$, thus providing additional support for the theory.

With respect to negotiation outcomes, the results indicated that $93.0 \%$ of Japanese dyads reached agreement $(n=40)$ whereas $74.5 \%$ of U.S. dyads reached agreement $(n=35)$. A logistical 
regression indicated that the odds ratio of agreement to non-agreement was significantly different in the United States and Japan, $\operatorname{Exp}(B)=4.57, p<.05$ (Exp = the estimated odds ratio). Of the dyads that reached agreement, Japanese achieved significantly higher profits than Americans, $F(1,73)=46.6, p<$ .01 (Japan $M=6,066.25$, U.S. $M=5,448.57$ ), which provides support for Hypothesis 5. Furthermore, selfserving biases of fairness were related to negotiation outcomes in that dyads with more egocentric perceptions achieved lower profits, $F(1,73)=4.82, \beta=-.26, p<.05$. Thus, as expected, U.S. participants had more egocentric perceptions of fairness than Japanese participants, and these perceptions were related to differences in profit.

Last, Hypothesis 6 predicted that negotiators in the U.S. would more readily accept feedback when they were told they were above-average performers and would more readily reject feedback when they were told they were average or below average. By contrast, we expected that Japanese negotiators would more readily accept negative as compared with positive feedback. In support of this, a MANOVA indicated a significant culture by condition interaction for the feedback items. As can be seen in Figure 2, U.S. negotiators in the positive condition were significantly more willing to accept responsibility for the feedback than in the equal or negative condition. By contrast, Japanese negotiators were significantly less willing to accept personal responsibility for the feedback in the positive condition, as compared with the negative or equal conditions, $F(2,174)=4.89, p<.01$. Likewise, as can be seen in Figure 3, U.S. negotiators had more confidence in the feedback in the positive than in the equal and negative conditions, whereas Japanese negotiators had more confidence in the feedback in the negative and equal conditions as compared with the positive condition, $F(2,174)=9.48, p<.01$. Figure 4 also shows that U.S. negotiators were significantly more willing to believe that the N.E.I. accurately reflected their skills in the positive condition as compared to either the negative or equal conditions Japanese 
negotiators were less willing to believe that the N.E.I. accurately reflected their skills as a negotiator in the positive condition, $F(2,174)=6.71, p<.01$.

\section{General Discussion}

In this article, we advanced a cultural view of self-serving biases of fairness in conflict and negotiation. We argued that cultural ideals in individualistic cultures focus on separating from others, being distinct, and feeling positive about oneself, whereas cultural ideals in collectivistic cultures focus on maintaining relatedness and adjusting one's behavior to fit in with others (Heine et al., 1999; Markus \& Kitayama, 1991). As a result, we expected that self-serving biases in negotiation would be more prevalent in individualistic cultures, in which the self is served by enhancing one's positive attributes to stand out and be better than others, as compared with collectivistic cultures, in which the self is served by focusing on one's weaknesses (described in emic Japanese terms as the process of hansei) to blend in and maintain interdependence with others.

Four studies, with different methods and different samples, illustrated that self-serving biases in conflict and negotiation are not as prevalent in other cultural contexts. Specifically, U.S. participants associated themselves with fair behaviors and others with unfair behaviors to a much greater extent than did Japanese participants (Study 1). Likewise, in a study of naturally occurring conflicts, in comparison to disputants in Japan, disputants in the United States projected their self-serving tendencies to an objective third party, whom they believed would view their behavior as much more fair than their counterparts' (Study 2). In the realm of negotiation, U.S. negotiators were more likely to perceive offers from their counterparts as unfair and to reject such offers, as compared with Japanese 
negotiators (Study 3). And in a more dynamic simulation, U.S. negotiators were more self-serving and achieved lower negotiation outcomes as compared with Japanese negotiators (Study 4). Indeed, U.S.

INSERT FIGURE 2 HERE

INSERT FIGURE 3 HERE

negotiators were also more accepting of feedback when it was self-serving and more rejecting of feedback when it was damaging to the self, whereas these tendencies were reversed among Japanese negotiators.

These findings have a number of important theoretical and practical implications. First, this research expands the dominant paradigm in negotiation research by directly testing whether aspects of negotiator cognition are universal (etic) or culture-specific (emic). This is crucial given that negotiation theory has been developed and tested almost exclusively in Western contexts (Pruitt \& Carnevale, 1993). Research on judgment biases in negotiation in particular serves as one of the foundations of the field (Bazerman, Curhan, Moore, \& Valley, 2000; Lewicki, Saunders, \& Minton, 1999), yet has largely been tested in the United States and Western Europe. In addition to testing the generality of our theories, this research forces us to question taken-for-granted assumptions in the field. To date, judgment biases have generally been assumed to be manifestations of cognitive shortcuts that

\section{INSERT FIGURE 4 HERE}

inevitably originate from the demands of overtaxed information processing systems. However, the research presented here suggests that judgment biases in negotiation can be reflections of different cultural ideals that negotiators have internalized as part of their self system. Along these lines, this 
research perhaps suggests a different view of "rationality" in negotiation. Cognitive biases are typically seen as irrational strategies based on attention to irrelevant information. However, given the U.S. cultural imperative of standing out, self-serving biases may be "rational," or normal adaptations to the cultural environment in individualistic cultures.

Second, this research makes a contribution to the science of negotiation by incorporating theories of the self into theory and research on negotiator cognition. In the past, there have been few explicit discussions of how negotiators' self-construals affect cognition about negotiation. This research illustrates that to understand self-serving judgment biases, it is crucial to understand the nature of the self among negotiators. Although we focused only on one judgment bias, we argue more generally that much of the research on judgment biases is based primarily on an independent view of the self, and as a result, the science of negotiation does not reflect the full range of human variation. For example, our results suggest that judgment biases such as reactive devaluation, escalation of commitment, or ignoring the cognitions of others (Bazerman, 1990) should be reevaluated in light of a cultural perspective, as they may be largely applicable in cultures that cultivate independent self-construals, wherein self-enhancement is natural and expected. Indeed, perhaps there are new judgment biases that have yet to be discovered but are more applicable to other cultures. For example, are group-serving biases more prevalent in negotiations in collectivist cultures? As a general proposition, we expect that the more the bias is linked to aspects of the self, as compared with, for example, pure numerical processing (e.g., anchoring), the more likely it is to be culture specific (see also Morris \& Gelfand, in press).

Our research also suggests new avenues for research on the social context in negotiation, an area that is increasing in its popularity (Kramer \& Messick, 1995; Kramer, in press). Because aspects of the self are activated by the social context (Fiske \& Taylor, 1991), we can develop specific and testable 
propositions regarding when self-serving biases (and other judgment phenomena) may be exacerbated across cultures. For example, because time pressure has been found to activate chronically accessible schemas (Ford \& Kruglanski, 1995), this situational condition may augment the psychological states that are chronically accessible in a particular culture (i.e., self-serving biases in individualistic cultures and self-effacement in collectivistic cultures). This perspective - that situational conditions activate culturally based schemas - provides a more dynamic view of culture in negotiation (Gelfand \& Realo, 1999; Morris \& Gelfand, in press).5

On a practical level, these findings further reinforce that U.S. negotiators are particularly susceptible to self-serving biases and that such biases impede negotiation outcomes. Previous research has illustrated that these biases are very difficult to reduce (Lewicki et al., 1999), and as a result, practitioners have been at a loss for how to de-bias negotiators. Indeed, in describing the dearth of good advice in this area, Lewicki et al. (1999) urged researchers "to identify other useful techniques for managing misperceptions and biases" (p. 164). The present research suggests a new approach for training to reduce such biases. Specifically, our results suggest that trainers can help negotiators understand how they have inter internalized cultural imperatives that can be maladaptive in negotiation contexts. In this respect, trainers can incorporate methods that have been useful in cross-cultural training, such as "cultural awareness training," into negotiation seminars on judgment biases. Grounding negotiation training in the larger cultural context may also mitigate defensiveness among negotiators in that it can help negotiators to see how they, as cultural citizens, have been trained in a number of institutions to stand out and to emphasize their positive attributes vis-a`-vis others. Of course, this "blame the culture" approach is an external attribution, which itself is self-serving! Yet training that helps negotiators understand how culture (which is often implicit) becomes operative in negotiations is nevertheless a new and promising approach to de-biasing. 
The current research also opens up specific avenues that trainers should explore to help de-bias negotiators during cultural awareness training. For example, because individuals' own fair behavior and others' unfair behavior is more accessible in memory (Study 1), trainers need to intervene to help negotiators attend to different sources of their own and others' behavior (i.e., their own unfair behavior and others' fair behavior) in conflicts. The present data (Study 4) also suggest that trainers need to work with negotiators to help them become more receptive to feedback on their performance. In this research, U.S. negotiators were resistant to accepting negative feedback yet readily accepted positive feedback. Because accepting accurate feedback is an important component of behavioral change, individuals in the United States may miss opportunities to understand the biases to which they are susceptible. Indeed, rejection of negative information is a mechanism for perpetuating self-serving biases, which may help explain the prevalence of self-serving biases in the United States. As such, interventions at the feedback stage may be important in reducing such biases. 6

Limitations

All research involves trade-offs (Cook \& Campbell, 1979), and in the current research, goals of precision and internal validity were prioritized. This research examined self-serving biases in conflict and negotiation among students in the laboratory, which raises the question of whether cross-cultural differences in self-serving biases will generalize to other populations outside of the laboratory. This is an important question that needs to be examined in future cross-cultural research.

We note, however, much cause for optimism that our results will generalize. Self-serving biases among Americans have been well documented among nonstudent populations outside of the laboratory. Self-serving biases are prevalent among professional negotiators, governmental decision 
makers, organizational consultants (de Dreu et al., 1995), public school teacher negotiators (Babcock et al., 1996), and married couples in conflict (Schuetz, 1999). Within organizations, self-serving biases are prevalent among customer service representatives and managers (Heath, 1999; Johns, 1994), management assessment center candidates (Clapham, 1998), applicants (Ployhart \& Ryan, 1998), employees (Mabe \& West, 1982), and even in letters to shareholders in annual reports (Staw, McKechnie, \& Puffer, 1983). Indeed, in his multilevel review of self-serving biases in organizations, Johns (1999) concluded that "there is ample evidence that self-serving occurs in the organizational domain" ( $p$. 4). Research also shows that self-serving biases are prevalent among a diverse array of populations, including ministers (Nauta, 1988), incarcerated delinquents (Barriga, Landau, Stinson, Liau, \& Gibbs, 2000), elementary school children (Snow, 1996), pilots (Wichman \& Ball, 1983), and even university faculty (McAllister, 1996)!

Likewise, there is evidence that differences in self-serving tendencies between Western and Japanese participants also apply beyond the laboratory and undergraduate samples. For example, Hess et al. (1986) found that in explaining poor performance, Japanese parents were more likely to focus on ways that children can improve themselves through effort (an internal attribution), whereas American parents were more likely to place blame on problematic schools and teachers (an external attribution; Kitayama \& Markus, 1995). Lower self-serving tendencies have been found among older Japanese professional students (age 30-60) as well (Muramoto \& Yamaguchi, 1997). Archival sources also reflect these cross-cultural differences: Attributions for events in newspaper articles have been found to be less self-serving in China as compared with the United States (Morris \& Peng, 1994). Likewise, Japanese newspapers focus more on mutual blame in conflicts than in American newspapers, which tend to put blame on one party (Gelfand et al., 2001). Thus, although caution should be exerted in applying our results to the field, we expect that there is ample reason to believe they will generalize. 
Another related issue is the use of questionnaire methods in the current research. Much of the research on self-serving biases uses questionnaire measures, which raises the possibility that our results could be attributed, at least in part, to participants' self-presentations in questionnaires. In other words, could Japanese respondents just be saying that they don't believe they are better than others when in fact, deep down, they feel differently? This is an important issue that has recently been discussed in the literature (Heine et al., 1999, 2000; Kitayama et al., 1997) and speaks to the validity of much of the research in cross-cultural organizational behavior that uses questionnaires. Although this is a difficult question to answer definitively, we note that research evidence suggests the contrary, for Japanese participants have been found to be self-critical even when anonymity is ensured (i.e., responses were not identifiable and were placed in boxes with other non-identifiable questionnaires; see Kitayama, 1999, as cited in Heine et al., 1999). Japanese participants also are self-critical in research that uses hidden behavioral measures that make socially desirable responses less of a possibility (Heine et al., 2000). Indeed, Kitayama et al. (1997) also illustrated that Japanese participants assume that others are self-critical, thereby providing additional evidence that effects found are not due merely to selfpresentation (see also Heine et al., 1999, for a review of this issue). In addition, in the current research, several of our measures of self-serving biases were relatively nonobtrusive, making the issue of selfpresentation less of a concern. This included, for example, ratings of the fairness of offers from other negotiators and the likelihood of acceptance of such offers in Study 3 and measures of free recall of fair and unfair behavior in Study 1. In addition, we also related cross-cultural differences in self-serving biases to objective outcomes (i.e., negotiation outcomes), which provides more confidence in the validity of our questionnaire measures.

Nevertheless, the reliance on questionnaire measures in cross-cultural research in general, and our research in particular, is an important issue that should be examined in future research. Although 
questionnaires are certainly a convenient method, there are nevertheless alternative methods that can be used. For example, reaction times and implicit attitude tests are nonobtrusive methods that would be interesting complements to questionnaire measures in future cross-cultural research. Finally, one last issue that merits attention is the use of difference scores in some of the studies, given that this method has been critiqued as being possibly unreliable. However, our results used multiple methods, some of which did not rely on this methodology (e.g., reactions to the self-serving feedback, recall of fair and unfair items), all of which provided strong convergence for our theory.

It is also important to note that our studies generally relied on static group designs, which is endemic to cross-cultural research given that individuals are not randomly assigned to their cultural groups. As with other static group designs, there could be other factors influencing our results, and furthermore, causality cannot be inferred. However, we can hold more confidence in our results given that they are based on theory and have been replicated across different methods. We can also place more confidence in our results given that we measured aspects of culture (Study 4) and directly linked variation in aspects of the self to self-serving biases and negotiation outcomes. By "unpackaging" culture and not relying exclusively on national comparisons, we were able to isolate aspects of culture that account for our effects.

At the same time, it is important to note that in the current research we examined only one dimension of culture. Future research should measure multiple aspects of culture to rule out the possibility that other cultural dimensions, such as power distance, are not accounting for results found. We note, however, that in the current research, it is unlikely that reduced self-serving biases among Japanese participants are merely a reflection of their deference to any authority judgment (i.e., a powerdistance explanation). For example, if power distance were the explanatory variable, then Japanese respondents should have been equally accepting of feedback from the expert (Study 4), regardless of 
the feedback condition. Yet our results show otherwise. Consistent with the notion that Japanese are more accepting of negative feedback to help them blend in, Japanese participants in the negative condition were significantly more accepting of the expert's feedback than participants in the equal or positive conditions. Nevertheless, future research should incorporate measures of multiple cultural dimensions in the study of negotiation in order to capture culture's complexity.

\section{Conclusion}

This research expands theory and research in the cognitive tradition within negotiation, and contributes to a growing literature on culture in social- organizational psychology and organizational behavior. Undoubtedly, as we continue to examine the nature of negotiator cognition in other cultures, we will be in a better position to develop a universal science-that which is inclusive of global human diversity. 
Notes

1. It is important to note that both independent and interdependent aspects of the self are available in individualist and collectivist cultures (Trafimow, Triandis, \& Goto, 1991). In other words, there is within-culture variation on these constructs as well. However, independent and interdependent self-construals are more likely to be chronically accessible in individualistic and collectivistic cultures, respectively (see Morris \& Gelfand, in press).

2. Although there has not been research on cultural influences on self-serving biases in the context of negotiation, there is increasing evidence that self-serving biases are attenuated in Japan in other domains, such as attributions and evaluations of performance (e.g., Al-Zahrani \& Kaplowitz, 1993; Hamilton, Blumenfeld, Akoh, \& Miura, 1990; Heine et al., 1999; Heine, Takata, \& Lehman, 2000; Heine et al., 2001; Hess, Chang, \& McDevitt, 1987; Fry \& Ghosh, 1980; Kashima \& Triandis, 1986; Morris \& Peng, 1994; Nurmi, 1992; Yan \& Gaier, 1994).

3. A copy of the feedback sheet can be obtained from Michele J. Gelfand. This manipulation was piloted in both the United States and Japan and was found to be effective. Samples in the positive feedback condition indicated that they were given above-average ratings, samples in the average feedback condition indicated they were given average ratings, and samples in the below-average feedback condition indicated that they were given below-average ratings.

4. Sample items of this scale include "I enjoy being unique and different from others in many respects," "I am comfortable with being singled out for praise or rewards," and "I feel it is important for me to act as an independent person." This instrument also includes another scale that assesses interdependent self-construals, which include items such as "I will sacrifice my self-interest for the benefit of the group I am in," "I feel good when I cooperate with others," and "My happiness depends on the happiness of those around me." It is surprising that the 
samples scored similarly on the interdependent scale (U.S. $M=67.71$; Japan $M=67.15$ ). We speculate that one reason why U.S. participants scored higher on interdependence than expected is for reasons similar to our research: U.S. participants may have been unwilling to report that they did not want to cooperate with others, that their happiness is not dependent on others, and so on. Nevertheless, our results do confirm that the U.S. participants rated independence items significantly higher than did Japanese participants, which is supportive of our theory. On the basis of these results, in the following analyses, we use the independent scale.

5. Indeed, recent work suggests that the situational context can moderate cultural differences in egocentrism. For example, Wade-Benzoni et al. (2002) investigated cultural differences in egocentrism in the domain of social dilemmas and found that, although there were trends that Japanese were less egocentric than Americans, the effect did not reach significance. Although future research will need to investigate the exact processes that account for cultural differences across negotiation and social dilemma contexts, we would speculate that a lack of mutual monitoring and a lack of a strong sanctioning system within the social dilemma task may have increased the activation of the independent self in Japan and thus attenuated cultural differences in egocentrism (see Yamagishi, 1988).

6. This is consistent with recent research by Babcock and colleagues, who found that asking individuals to identify weaknesses in their own cases can reduce self-serving biases in conflict (see Babcock \& Loewenstein, 1997). Conceptually, this intervention fits with our theory regarding cultural systems and self-serving biases; that is, because of an emphasis on "blending in," Japanese negotiators may more naturally and spontaneously identify their own weaknesses, thereby reducing self-serving biases in conflicts. 

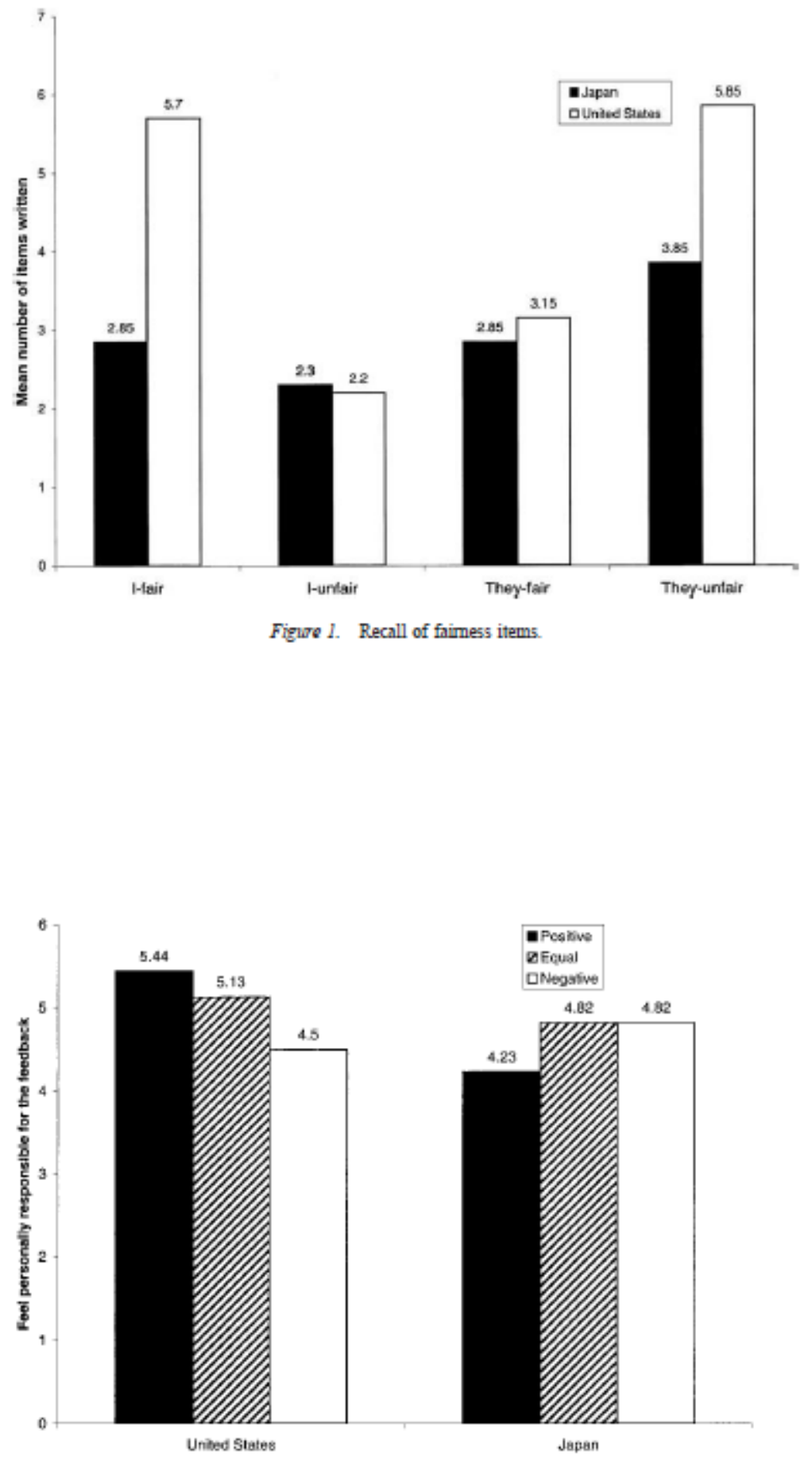

Figure 2. To what extent do you feel personally responsible for the feedback? 
Culture and Egocentric Perceptions of Fairness in Conflict and Negotiation 33

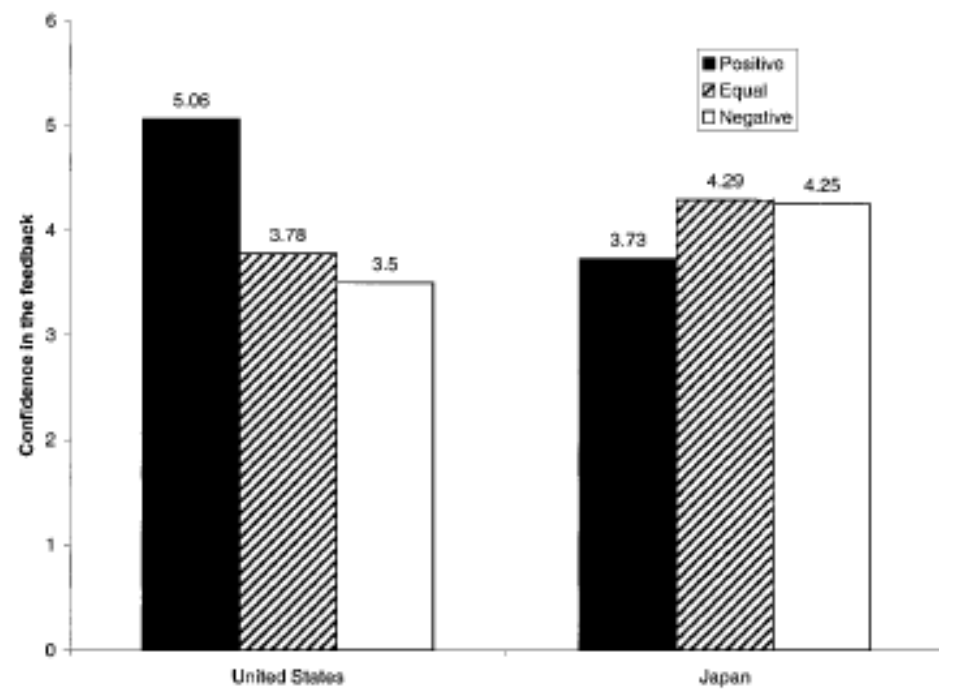

Figure 3. How confident are you that the feedback accurately reflects your abilities?

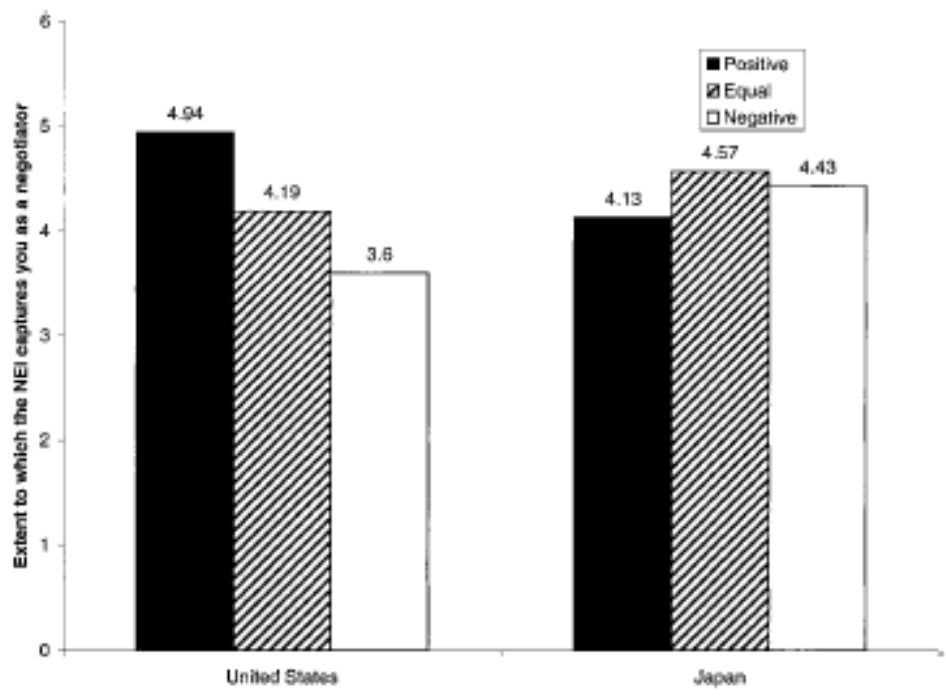

Figure 4. To what extent does the NEI capture you as a negotiator? NEI - Negotiation Effectiveness Index. 
Culture and Egocentric Perceptions of

Fairness in Conflict and Negotiation

34

Appendix A

Negotiation Issue Charts (Studies 3 and 4)

\begin{tabular}{|c|c|c|c|}
\hline Discount & Colors & Billing & Circulation \\
\hline \multicolumn{4}{|c|}{ The Gallery Issue Chart (Buyers) } \\
\hline $\begin{array}{c}20 \% \text { off }-\$ 2,400 \\
15 \% \text { off }-\$ 1, \$ 00 \\
10 \% \text { off }-\$ 1,200 \\
5 \% \text { off }-\$ 500 \\
0 \% \text { off }-\$ 0\end{array}$ & $\begin{array}{c}4 \text { colors }-\$ 2,000 \\
3 \text { colors }-\$ 1,500 \\
2 \text { colors }-\$ 1,000 \\
1 \text { color }-\$ 500 \\
\text { N0 color }-\$ 0\end{array}$ & $\begin{array}{c}5 \text { weeks }-\$ 1,200 \\
4 \text { weeks }-\$ 900 \\
3 \text { weeks }-\$ 600 \\
2 \text { weeks }-\$ 300 \\
1 \text { week }-\$ 0\end{array}$ & $\begin{array}{l}500,000-\$ 4,000 \\
400,000-\$ 3,000 \\
300,000-\$ 2,000 \\
200,000-\$ 1,000 \\
100,000-\$ 0\end{array}$ \\
\hline \multicolumn{4}{|c|}{ NDC Printing Issue Chart (Sellers) } \\
\hline $\begin{array}{l}20 \% \text { off }-\$ 0 \\
15 \% \text { off }-\$ 500 \\
10 \% \text { off }-\$ 1,200 \\
5 \% \text { off }-\$ 1,800 \\
0 \% \text { off }-\$ 2,400\end{array}$ & $\begin{array}{c}4 \text { colors }-\$ 0 \\
3 \text { colors }-\$ 500 \\
2 \text { colors }-\$ 1,000 \\
1 \text { color }-\$ 1,500 \\
\text { No color }-\$ 2,000\end{array}$ & $\begin{array}{l}5 \text { weeks }-\$ 0 \\
4 \text { weeks }-\$ 1,000 \\
3 \text { weeks }-\$ 2,000 \\
2 \text { weeks }-\$ 3,000 \\
1 \text { week }-\$ 4,000\end{array}$ & $\begin{array}{l}500,000-\$ 0 \\
400,000-\$ 300 \\
300,000-\$ 600 \\
200,000-\$ 900 \\
100,000-\$ 1,200\end{array}$ \\
\hline
\end{tabular}


References

Al-Zahrani, S. S. A., \& Kaplowitz, S. A. (1993). Attributional biases in individualistic and collectivistic cultures: A comparison of Americans with Saudis. Social Psychology Quarterly, 56, 223-233.

Babcock, L., \& Loewenstein, G. (1997). Explaining bargaining impasse: The role of self-serving biases. Journal of Economic Perspectives, 11, 109-125.

Babcock, L., Wang, X., \& Loewenstein, G. (1996). Choosing the wrong pond: Social comparisons that reflect a self-serving bias. Quarterly Journal of Economics, 111, 1-19.

Barriga, A. Q., Landau, J. R., Stinson, B. L., Liau, A. K., \& Gibbs, J. C. (2000). Cognitive distortion and problem behaviors in adolescents. Criminal Justice \& Behavior, 27, 36-56.

Bazerman, M. H. (1990). Judgment in managerial decision making. New York: Wiley.

Bazerman, M. H., \& Carroll, J. S. (1987). Negotiator cognition. In B. M. Staw \& L. L. Cummings (Eds.), Research in organizational behavior (Vol. 9, pp. 247-288). Greenwich, CT: JAI Press.

Bazerman, M. H., Curhan, J. R., Moore, D. A., \& Valley, K. L. (2000). Negotiation. Annual Review of Psychology, 51, 279-314.

Clapham, M. M. (1998). A comparison of assessor and self dimension ratings in an advanced management assessment center. Journal of Occupational and Organizational Psychology, 71, 193-203.

Cook, T. D., \& Campbell, D. T. (1979). Quasi-experimentation: Design and analysis issues for field settings. Boston: Houghton Mifflin.

de Dreu, C. K. W., Nauta, A., \& Van de Vliert, E. (1995). Self-serving evaluations of conflict behavior and escalation of the dispute. Journal of Applied Social Psychology, 25, 2049-2066. 
Fiske, S. T., \& Taylor, S. E. (1991). Social cognition (2nd ed.). New York: McGraw-Hill.

Friedrich, J. (1996). On seeing oneself as less self-serving than others: The ultimate self-serving bias. Teaching of Psychology, 23, 107-109.

Ford, T. E., \& Kruglanski, A. W. (1995). Effects of epistemic motivation on the use of accessible constructs in social judgment. Personality and Social Psychology Bulletin, 21, 950-962.

Fry, P. S., \& Ghosh, R. (1980). Attributions of success and failure: Comparison of cultural differences between Asian and Caucasian children. Journal of Cross-Cultural Psychology, 11, 343-363.

Gelfand, M. J., Nishii, L. H., Holcombe, K., Dyer, N., Ohbuchi, K., \& Fukumo, M. (2001). Cultural influences on cognitive representations of conflict: Interpretations of conflict episodes in the United States and Japan. Journal of Applied Psychology, 86, 1059-1074.

Gelfand, M. J., \& Realo, A. (1999). Individualism- collectivism and accountability in intergroup negotiations. Journal of Applied Psychology, 84, 721-736.

Hamilton, V. L., Blumenfeld, P. C., Akoh, L., \& Miura, K. (1990). Credit and blame among Japanese and American children: Normative, cultural, and individual differences. Journal of Personality and Social Psychology, 59, 442-451.

Harter, S. (1990). Causes, correlates, and the functional role of global self worth: A life span perspective. In R. J. Sternberg \& J. Kollingen, Jr. (Eds.), Competence considered (pp. 67-97). New Haven, CT: Yale University Press.

Heath, C. (1999). On the social psychology of agency relationships: Lay theories of motivation overemphasize extrinsic incentives. Organizational Behavior and Human Decision Processes, 78, $25-62$. 
Heine, S. J., \& Lehman, D. R. (1995). Cultural variation in unrealistic optimism: Does the West feel more invulnerable than the East? Journal of Personality and Social Psychology, 68, 595-607.

Heine, S. J., \& Lehman, D. R. (1999). Culture, self-discrepancies, and self-satisfaction. Personality and Social Psychology Bulletin, 25, 915-925.

Heine, S. J., Lehman, D. R., Markus, H. R., \& Kitayama, S. (1999). Is there a universal need for positive self-regard? Psychological Review, 106, 766-794.

Heine, S. J., Kitayama, S., Lehman, D. R., Takata, T., Ide, E., Leung, C., \& Matsumoto, H. (2001). Divergent consequences of success and failure in Japan and North America: An investigation of selfimproving motivation and malleable selves. Journal of Personality and Social Psychology, 81, 599-615.

Heine, S. J., Takata, T., \& Lehman, D. R. (2000). Beyond self-presentation: Evidence for self-criticism among Japanese. Personality and Social Psychology Bulletin, 26, 71-78.

Hess, R., Azuma, H., Kashiwagi, K., Dickson, W. P., Nagano, S., Holloway, S., et al. (1986). Family influences on school readiness and achievement in Japan and the U.S.: An overview of a longitudinal study. In H. Stevenson, H. Azuma, \& K. Hakuta (Eds.), Child development and education in Japan (pp. 147-166). New York: Freeman.

Hess, R. D., Chang, C. M., \& McDevitt, T. M. (1987). Cultural variables in family beliefs about children's performance in mathematics: Comparisons among People's Republic of China, ChineseAmerican, and Caucasian-American families. Journal of Educational Psychology, 79, 179-188.

Hofstede, G. (1980). Culture's consequences: International differences in work-related values. Beverly Hills, CA: Sage. 
Johns, G. (1994). Absenteeism estimates by employees and managers: Divergent perspectives and selfserving perceptions. Journal of Applied Psychology, 79, 229-239.

Johns, G. (1999). A multi-level theory of self-serving behavior in and by organizations. In R. I. Sutton \& B. M. Staw (Eds.), Research in Organizational Behavior, 21, 1-38.

Kashima, Y., \& Callan, V. J. (1994). The Japanese work group. In H. C. Triandis, M. Dunnette, \& L. M. Hough (Eds.), Handbook of industrial and organizational psychology (2nd ed., Vol. 4, pp. 609626). Palo Alto, CA: Consulting Psychologists Press.

Kashima, Y., \& Triandis, H. C. (1986). The self-serving bias in attributions as a coping strategy: A crosscultural study. Journal of Cross-Cultural Psychology, 17, 83-97.

Kitayama, S., \& Markus, H. R. (1995). Culture and self: Implications for internationalizing psychology. In N. R. Goldberger \& J. B. Veroff (Eds.), The culture and psychology reader (pp. 366-383). New York: New York University Press.

Kitayama, S., Markus, H. R., Matsumoto, H., \& Norasakkunkit, V. (1997). Individual and collective processes in the construction of the self: Self-enhancement in the United States and selfcriticism in Japan. Journal of Personality and Social Psychology, 72, 6, 1245-1267.

Kramer, R. (in press). A 'dark side' of social context: Exploring the role of paranoia in intergroup negotiations. In M. J. Gelfand \& J. M. Brett (Eds.), Negotiation and Culture: Integrative perspectives to theory and research. Palo Alto, CA: Stanford University Press.

Kramer, R. M., \& Messick, D. M. (1995). Negotiation as social process. Thousand Oaks, CA: Sage. 
Kramer, R. M., Newton, E., \& Pommerenke, P. L. (1993). Self-enhancement biases and negotiator judgement: Effects of self-esteem and mood. Organizational Behavior and Human Decision Processes, 56, 110-133.

Lewicki, R. J., Saunders, D. M., \& Minton, J. W. (1999). Negotiation (3 ${ }^{\text {rd }}$ ed.). Boston: McGraw-Hill.

Lewinsohn, P. M., Mischel, W., Chaplin, W., \& Barton, R. (1980). Social competence and depression: The role of illusory self-perceptions. Journal of Abnormal Psychology, 89, 203-212.

Loewenstein, G., Issacharoff, S., Camerer, C., \& Babcock, L. (1993). Self-serving assessments of fairness and pretrial bargaining. Journal of Legal Studies, 22, 135-159.

Mabe, P. A., III, \& West, S. G. (1982). Validity of self-evaluation of ability: A review and meta-analysis. Journal of Applied Psychology, 67, 280-296.

Mark, M. M., Mutrie, N., Brooks, D. R., \& Harris, D. V. (1985). Causal attributions of winners and losers in individual competitive sports: Toward a reformulation of the self-serving bias. Journal of Sport Psychology, 6, 184-196.

Markus, H. R., \& Kitayama, S. (1991). Culture and the self: Implications for cognition, emotion, and motivation. Psychological Review, 98, 224- 253.

Markus, H. R., Kitayama, S., \& Heiman, R. J. (1996). Culture and "basic" psychological principles. In E. T. Higgins \& A. W. Kruglanski (Eds.), Social psychology: Handbook of basic principles (pp. 857-913). New York: Guilford Press.

Markus, H. R., Mullally, P. R., \& Kitayama, S. (1997). Selfways: Diversity in modes of cultural participation. In U. Neisser \& D. Jopling (Eds.), The conceptual self in context: Culture, experience, self-understanding (pp. 13-61). New York: Cambridge University Press. 
McAllister, H. A. (1996). Self-serving bias in the classroom: Who shows it? Journal of Educational Psychology, 88, 123-132.

Messick, D. M., Bloom, S., Boldizar, J. P., \& Samuelson, C. D. (1985). Why we are fairer than others. Journal of Experimental Social Psychology, 21, 480-500.

Miller, D. T., \& Ross, M. (1975). Self-serving biases in the attribution of causality: Fact or fiction? Psychological Bulletin, 82, 213-225.

Morris, M., \& Gelfand, M. J. (in press). Cultural differences and cognitive dynamics: Expanding the cognitive perspective on negotiation. In M. J. Gelfand \& J. M. Brett (Eds.), Negotiation and culture: Integrative approaches to theory and research. Stanford, CA: Stanford University Press.

Morris, M., \& Peng, K. (1994). Culture and cause: American and Chinese attributions for social and physical events. Journal of Personality and Social Psychology, 67, 949-971.

Muramoto, Y., \& Yamaguchi, S. (1997). Another type of self-serving bias: Coexistence of self-effacing and group-serving tendencies in attribution in the Japanese culture. Japanese Journal of Experimental Social Psychology, 37, 65-75.

Nauta, R. (1988). Task performance and attributional biases in the ministry. Journal for the Scientific Study of Religion, 27, 609-620.

Nurmi, J. (1992). Cross-cultural differences in self-serving bias: Responses to the attributional style questionnaire by American and Finnish students. Journal of Social Psychology, 132, 69-76.

Ployhart, R. E., \& Ryan, A. M. (1998). Toward an explanation of applicant reactions: An examination of organizational justice and attribution frameworks. Organizational Behavior and Human Decision Processes, 72, 308-335. 
Pruitt, D. G. (1981). Negotiation behavior. New York: Academic Press.

Pruitt, D. G., \& Carnevale, P. J. (1993). Negotiation in social conflict. Buckingham, England: Open University Press.

Schuetz, A. (1999). It was your fault! Self-serving biases in autobiographical accounts of conflicts in married couples. Journal of Social and Personal Relationships, 16, 193-208.

Singelis, T. M. (1994). The measurement of independent and interdependent self-construals. Personality and Social Psychology Bulletin, 20, 580-591.

Snow, R. D. (1996). The self-serving bias in children. Dissertation Abstracts International, 56, 6422.

Staw, B., McKechnie, P. I., \& Puffer, S. M. (1983). The justification of organizational performance. Administrative Sciences Quarterly, 28, 582-600.

Stillenger, C., Epelbaum, M., Keltner, D., \& Ross, L. (1991). The "reactive devaluation" barrier to conflict resolution. Manuscript in preparation, Stanford University, Palo Alto.

Takata, T. (1987). Self-depracative tendencies in self-evaluation through social comparison. Japanese Journal of Experimental Social Psychology, 27(1), 27-36.

Thompson, L. L. (1990). Negotiation behavior and outcomes: Empirical evidence and theoretical issues. Psychological Bulletin, 108, 515-532.

Thompson, L. L., \& Hastie, R. (1990). Social perception in negotiation. Organizational Behavior and Human Decision Processes, 47, 98-123.

Thompson, L. L., \& Hrebec, D. (1996). Lose-lose agreements in interdependent decision making. Psychological Bulletin, 120, 396-409. 
Thompson, L., \& Loewenstein, G. (1992). Egocentric interpretations of fairness and interpersonal conflict. Organizational Behavior and Human Decision Processes, 51, 176-197.

Thompson, L., Valley, K. L., \& Kramer, R. (1995). The bittersweet feeling of success: An examination of social perception in negotiation. Journal of Experimental Social Psychology, 31, 467-492.

Trafimow, D., Triandis, H. C., \& Goto, S. G. (1991). Some tests of the distinction between the private self and the collective self. Journal of Personality and Social Psychology, 60, 649-655.

Triandis, H. C. (1995). Individualism and collectivism. New York: Simon \& Schuster. Urban, M. S., \& Witt, L. A. (1990). Self-serving bias in group member attributions of success and failure. Journal of Social Psychology, 130, 417-418.

Wade-Benzoni, K. A., Okumura, T., Brett, J. M., Moore, D. A., Tenbrunsel, A. E., \& Bazerman, M. H. (2002). Cognitions and behavior in asymmetric social dilemmas: A comparison of two cultures. Journal of Applied Psychology, 87, 87-95.

White, J. A., \& Plous, S. (1995). Self-enhancement and social responsibility: On caring more, but doing less, than others. Journal of Applied Social Psychology, 25, 1297-1318.

Wichman, H., \& Ball, J. (1983). Locus of control, self-serving biases, and attitudes towards safety in general aviation pilots. Aviation, Space, \& Environmental Medicine, 54, 507-510.

Yamagishi, T. (1988). Exit from the group as an individualistic solution to the free rider problem in the United States and Japan. Journal of Experimental Social Psychology, 24, 530-542.

Yan, W., \& Gaier, E. L. (1994). Causal attributions for college success and failure: An Asian-American comparison. Journal of Cross-Cultural Psychology, 25, 146-158. 